Z. klin. Chem. u. klin. Biochem.

7. Jg., S. 530-539, September 1969

\title{
Kinetischer Test zur Bestimmung der Serumlipaseaktivität
}

\author{
Von W. Rick \\ I. Mediqinische Klinik der Universität Düsseldorf (Direktor: Prof. Dr. F. Grosse-Brockboff)
}

(Eingegangen am 2. Juli 1969)

Zur Bestimmung der Aktivität der lipolytischen Enzyme des Serums eignet sich ein kinetischer Test mit einer Emulsion von Olivenöl in Gummi arabicum-Lösung als Substrat. Die durch die Enzymwirkung freigesetzten Fettsäuren werden mit Hilfe einer ausreichend empfindlichen Meßanordnung bei konstantem $\mathrm{pH}$ kontinuierlich titriert. Unter Berücksichtigung der Empfehlungen der Enzymkommission der Internationalen Union für Biochemie dient $25^{\circ} \mathrm{C}$ als Meßtemperatur; für Substratkonzentration, $\mathrm{pH}$ und Aktivatorkonzentrationen konnten optimale Bedingungen ausgearbeitet werden. Die Angabe der Enzymaktivität erfolgt in Internationalen Einheiten (U), wobei $1 \mathrm{U}$ der Freisetzung von $1 \mu$ Val Fettsäuren pro Minute unter optimalen Bedingungen entspricht. Die an Seren pankreasgesunder Probanden ermittelten Aktivitäten zeigen eine logarithmisch-normale Verteilung, die sich durch die Werte $\overline{\mathbf{x}}=60 \mathrm{mU} / \mathrm{ml}$, $\overline{\mathrm{x}}-2 \mathrm{~s}=20 \mathrm{mU} / \mathrm{m} l$ und $\overline{\mathrm{x}}+2 \mathrm{~s}=160 \mathrm{mU} / \mathrm{m} /$ beschreiben läßt. Im Serum von Patienten mit akuter Pankreatitis fanden sich Aktivitäten von $1000 \mathrm{bis} 20600 \mathrm{mU} / \mathrm{ml}$.

\section{$A$ kinetic method for the determination of serum lipase activity}

The activity of the lipolytic enzymes of serum was measured kinetically, using an emulsion of olive oil in a solution of gum arabic as substrate. The enzymic release of fatty acids was determined by titration at constant $\mathrm{pH}$, under conditions designed to give an appropriate sensitivity. The incubation temperature was $25^{\circ}$, in accordance with the recommendations of the enzyme commission of the International Union of Biochemistry; the optimal conditions of substrate concentration, $\mathrm{pH}$ and activator concentrations were determined. Enzyme activity was expressed in International Units $(U)$, where $1 U$ corresponds to the release of $1 \mu$ equiv. fatty. acids per min. under optimal conditions. The sera from pancreatically normal probands gave activities with a logarithmic-normal scatter, characterised by the values: $\overline{\mathrm{x}}=60 \mathrm{mU} / \mathrm{ml}, \overline{\mathrm{x}}-2 \mathrm{~s}=20 \mathrm{mU} / \mathrm{ml}$ and $\overline{\mathrm{x}}+2 \mathrm{~s}=160 \mathrm{mU} / \mathrm{m} l$. The sera of patients with acute pancreatitis showed activities of 1000 to $20600 \mathrm{mU} / \mathrm{ml}$.

Triglycerid-spaltende Enzyme (Glycerinester-Hydrolasen, EC 3.1.1.3) kommen praktisch in allen Säugetierorganen vor (Übersicht bei (1)). Im folgenden wird unter Serumlipase die Summe der im Serum enthaltenen lipolytischen Enzyme unabhängig von ihrer Herkunft verstanden. $\mathrm{Da}$ - mit Ausnahme der Lipase aus Schweinepankreas (2) - bisher nur Aktivitäten, aber keine einheitlichen Enzymproteine untersucht wurden, sind Substrat- und Inhibitorspezifität sowie weitere Eigenschaften der lipolytischen Enzyme noch weitgehend ungeklärt. Im Gegensatz zu Carboxyl-Esterase (Carboxylester-Hydrolase, EC 3.1.1.1) (3) wirkt Pankreaslipase nur auf wasserunlösliche, emulgierte Substrate, vor allem Triglyceride mit langkettigen Fettsäuren ein (4). $\mathrm{Da}$ einerseits das Pankreas das lipasereichste Organ darstellt, andererseits die Diagnostik und Verlaufskontrolle der akuten Pankreatitis an Hand von Bestimmungen der Amylaseaktivität nicht optimal erscheint, wurden in der Literatur zahlreiche Verfahren. zur Bestimmung der Lipaseaktivität beschrieben. Berücksichtigt man die Angaben von Desnuelie und Savary (4) zur Spezifität des Enzyms, so sind alle wasserlöslichen Substanzen (z. B. 5-10) als Substrate ungeeignet. Unter den wasserunlöslichen ist vor allem Olivenöl von zahlreichen Autoren benutzt worden (11-21).

$\mathrm{Da}$ die Lipaseaktivität im Serum des Gesunden sehr gering ist, muß lange (1-24 Stdn.) inkubiert und der Testansatz ausreichend gepuffert werden. Als $\mathrm{Maß}$ der Enzymaktivität bei diesen diskontinuierlichen Testen dient die durch Titration ermittelte Menge freigesetzter
Fettsäuren. Dabei wird der Puffer mittitriert, so daß sich hohe Leerwerte ergeben und wegen der niedrigen Aktivitäten dàs Verhältnis zwischen Leerwert und Bestimmung ungünstig ist. Ebenso wie bei der von Marchis-Mouren, Sarda und Desnuelle (2) angegebenen Vorschrift werden in dem hier entwickelten Ansatz die freigesetzten Fettsäuren kontinuierlich titriert, und das optimale $\mathrm{pH}$ wird durch Zugabe äquivalenter Mengen Natronlauge während der gesamten Meßdauer eingehalten. $\mathrm{Da}$ in einem solchen kinetischen Test die Messung der Anfangsgeschwindigkeit der Reaktion möglich ist, läßt sich die Wirkung zugesetzter Aktivatoren oder Inhibitoren sicherer beurteilen als bei diskontinuierlichen Verfahren, bei denen sich Wirkungen auf die Enzymaktivität, auf die Stabilität des Enzymmoleküls und auf die Substratemulsion überschneiden können.

Auf Grund der Empfehlungen der Enzymkommission der Internationalen Union für Biochemie (22) wurde $25^{\circ} \mathrm{C}$ als Meßtemperatur gewählt. Für Substratkonzentration, $\mathrm{pH}$ und Aktivatoren konnten optimale Bedingungen ausgearbeitet werden. Das Prinzip des Verfahrens und diese Bedingungen wurden bereits kurz mitgeteilt (23).

\section{Methodik}

\section{Prinzip}

Die durch die lipolytischen Enzymeides Serums aus einer Olivenölemulsion bei $25^{\circ}$ unter optimalen Bedingungen freigesetzten Fettsäuren werden bei pH 8,6 kontinuierlich mit Alkali titriert. Dadurch wird das für die enzymatische Reaktion optimale $\mathrm{pH}$ 
konstant gehalten, so daß keine Puffersubstanzen zugesetzt werden müssen. Das pH des Inkubationsansatzes wird mit der Glaselektrode gemessen, als Bezugselektrode dient eine gesättigte Kalomelelektrode. Die Zugabe des Alkali wird durch den von Jacobsen, Leonis, Linderström-Lang und OtTresen (24) angegebenen Titrator gesteuert und registriert. Gummi arabicum als inertes Polysaccharid dient zur Erzielung einer stabilen Olivenölemulsion, Natrium-Glykocholat in optimaler Konzentration als Aktivator.

\section{Reagenzien}

1. Gummi arabisch, ausgelesen, fein gepulvert (Merck 4282)

2. Olivenöl DAB 6 bzw. DAB 7

3. Glykocholsäure purum (Fluka 54266)

4. Bidest. Wasser Kohlendioxyd-frei

5. $\mathrm{N} \mathrm{NaOH}$

6. $0,1 \mathrm{~N} \mathrm{NaOH}$

7. $0,01 \mathrm{~N} \mathrm{NaOH}$

8. $\mathrm{N} \mathrm{HCl}$

9. 0,1N Oxalsäurelösung (Merck 9965/0001)

10. Kontrollserum (Enza-trol, Dade Reagents Inc.)

11. Stickstoff, Kohlendioxyd-frei (Kohlendioxyd-Gehalt evtl. mit Bariumhydroxyd kontrollieren)

12. Eichpuffer
a) Präzisionspuffer Radiometer $S 1510$, bei $25^{\circ} \mathrm{pH} 7,41$
b) Präzisionspuffer Radiometer S 1500 , bei $25^{\circ} \mathrm{pH} 6,865$
c) Phosphatpuffer 0,025 $\mathrm{M} \mathrm{pH} \mathrm{6,88} \mathrm{(Merck} \mathrm{7294)}$

13. Olsäure, etwa 99 proz. (Sigma, Best.-Nr. 0 0750).

\section{Lösungen}

Gummi arabicum-Lösung (10 proz. (w/v) in bidest. Wasser)

$50 \mathrm{~g}$ Gummi arabicum und etwa $450 \mathrm{~m} /$ bidest. Wasser im Starmix (Stufe I) so lange mischen, bis die Substanz vollständig gelöst ist (etwa 15 Min.). Lösung dann in einen $500 \mathrm{ml}$ Meßzylinder überführen und mit bidest. Wasser auf $500 \mathrm{ml}$ auffüllen, Lösung gut mischen.

Nach einigen Stunden findet sich im Meßzylinder ein Bodensatz, die überstehende, gering getrübte Lösung wird in eine Polyäthylenflasche abgegossen und bei $+4^{\circ}$ aufbewahrt. (Mindestens 4 Wochen haltbar.)

\section{Olivenölemulsion}

Im Meßzylinder mischen:

4 Teile 10 proz. Gummi arabicum (z. B. $400 \mathrm{~m} /$ )

1 Teil Olivenöl DAB 6 bzw. 7 (z. B. $100 \mathrm{ml}$ ).

Mischung 5 Min. im Starmix (Stufe II) homogenisieren, etwa $5 \mathrm{ml} \mathrm{N} \mathrm{NaOH}$ zugeben und nochmals $2 \mathrm{Min}$. homogenisieren. Das $\mathrm{pH}$ der Substratlösung wird anschließend mit $\mathrm{N} \mathrm{HCl}$ auf etwa $\mathrm{pH} 9$ gebracht.

Lösung gut verschlossen im Kühlschrank aufbewahren, etwa 1 Woche haltbar.

Sollte eine leichte Substratentmischung auftreten, empfiehlt sich nochmaliges kurzes Homogenisieren.

Na-Glykeocholatlösung, $75 \mathrm{~mm}$

Im $50 \mathrm{~m} l$-Becherglas

$1,87 \mathrm{~g}$ Glykocholsäure (Fluka) in 3,8 $\mathrm{m} l \mathrm{~N} \mathrm{NaOH}$ und etwa $40 \mathrm{ml}$ bidest. Wasser lösen (Magnetrührer). Nach vollständiger Lösung $\mathrm{pH}-$ Wert mit $\mathrm{N} \mathrm{NaOH}$ auf etwa $\mathrm{pH}$ 8,6 einstellen. Inhalt des Becherglases quantitativ mit bidest. Wasser in einen $50 \mathrm{ml}-\mathrm{Me}$ kolben überführen, mit bidest. Wasser auf $50 \mathrm{ml}$ auffüllen und umschütteln. Evtl. vorhandene feine Fäserchen in der Lösung können abzentrifugiert werden.

Bei 0 bis $+4^{\circ}$ aufbewahrt einige Monate haltbar.

Bidest. Wasser, Koblendioxyd-frei

Bidest. Wasser in einer Kochflasche mit NS 29,5 mehrere Min. bei $100^{\circ}$ halten, mit Natronkalkrohr verschlossen abkühlen lassen.

\section{$0,01 \times \mathrm{NaOH}$}

Ein $100 \mathrm{ml}$-Meßkolben wird bis zur Marke mit $0,1 \mathrm{~N} \mathrm{NaOH}$ gefüllt. Die abgemessene Natronlauge wird mit Kohlendioxydfreiem bidest. Wasser quantitativ in einen $1000 \mathrm{~m} /$-Meßkolben überführt und mit Kohlendioxyd-freiem bidest. Wasser bis zur Marke aufgefüllt. Gut schütteln! Aufbewahrung in einem luftdicht abgeschlossenen Vorratsgefä $\beta$, das an die Autobürette angeschlossen wird. Die in das Vorratsgefäß nachströmende Raumluft wird durch Vorschalten einer Flasche mit Natronkalk von Kohlendioxyd gereinigt und durch Vorschalten einer weiteren, mit Wasser gefüllten Flasche mit Wasserdampf gesättigt.

\section{Meßanordnung}

Folgende Geräte und Zubehörteile wurden verwendet:

Radiometer AG Kopenhagen:

1. $\mathrm{pH}-$ Meter 26 mit Titrator 11

2. Autobürette ABU 1 mit Büretteneinheit B 160, entsprechend einem verfügbaren Titrationsvolumen von $250 \mu l$

3. Titrigraph SBR 2,

$25 \mathrm{~cm}$ Schreibbreite $=250 \mu l$ Titrationsflüssigkeit, entsprechend $100 \%$ des Bürettenkolben-Vorschubs

\section{Elektroden}

Glaselektrode G $202 \mathrm{C}$ bzw.

Glaselektrode G 2222 C

Kalomelelektrode K 4112

5. Bürettenspitze (Glaskapillare) D 4331

6. Kunststoffspitze für Stickstoffzufuhr

7. Als Halterung für die Elektroden (4), Bürettenspitze (5) und Kunststoffspitze für Stickstoffzufuhr (6) dient der Elektrodenkopf der Mikro-Titrationszusammenstellung TTA 31

8. Titrationsgefäße

a) Zur Ermittlung des Faktors der 0,01N $\mathrm{NaOH}$ : Mikrotitrationsgefäß V 521 mit zugehörigen Rührmagneten

b) Für enzymatische Reaktionen:

$25 \mathrm{~m}$-Bechergläser mit eng passendem Temperiergefäß aus Kupfer

Gummi-Abdichtung gegen den Elektrodenkopf

Janke und Kunkel:

Magnetrührer RCHR

Magnetstäbchen $25 \mathrm{~mm}$ Länge, $9 \mathrm{~mm}$ Durchmesser

Gebrüder Haake:

Ultrathermostat

Sämtliche Geräte einschließlich Magnetrührer und Temperiergefäß sind an eine Grunderde angeschlossen. Zur Vermeidung elektrostatischer Störungen durch Kunststofftischplatten kann die ganze Anlage auf einer geerdeten Metallfolie aufgebaut werden. Die Abschirmung gegen äußere Einflüsse wird weiterhin durch Zusatz von Kaliumnitrat (Endkonz. 0,2\% (w/v)) zum Wasser im Thermostaten verbessert.

Es ist anzunehmen, daß die Bestimmung auch mit Meßgeräten anderer Hersteller ausgeführt werden kann; eigene Erfahrungen hierüber liegen jedoch nicht vor.

Eichung

Zur Eichung benutzten wir Präzisionspuffer und eichten die Elektroden mit den dafür vorgesehenen Regelpotentiometern auf 0,01 $\mathrm{pH}$-Einheit absolut.

\section{Ermittlung des Faktors der 0,01 N $\mathrm{NaOH}$}

Das auf $25^{\circ}$ temperierte Titrationsgefä $\beta$ wird mit $1,0 \mathrm{~m} /$ Kohlendioxyd-freiem bidest. Wasser beschickt. Durch Titration mit $0,01 \mathrm{~N} \mathrm{NaOH}$ wird das bidest. Wasser auf $\mathrm{pH} 7,0$ eingestellt. Zum Schutz gegen das Kohlendioxyd der Luft wird ein gleichmäßiger Strom Stickstoff über die Flüssigkeit im Titrationsgefäß geleitet. $20 \mu l 0,1 \mathrm{~N}$ Oxalsäure mit einer geeichten SANZ-Pipettc in das Titrationsgefäß geben; die Titrationskurve dieser Säure wird nach Vorschrift registricrt. 
Ansatz zur Enzymaktivitätsbestimmung

Einstellungen am pH-Meter:

Temperaturkompensation ,internal“; Temperatur $25^{\circ}$

Einstellungen am Titrator:

Endpunkt 8,6; Selector ,,up scale“; Proportionalband 0,05

Einstellung an der Autobürette:

Je nach Enzymaktivität „Speed“ 1-16 wählen

Einstellungen am Titrigraphen:

Für den Papiervorschub wurde der Motor 4 U/Min. benutzt und die Getriebeschaltung von $2,5 \mathrm{~mm} / \mathrm{U}$., was einer Geschwindigkeit von $10 \mathrm{~mm}$ pro Min. entspricht. Die Bürettengeschwindigkeit war auf 1 geschaltet, entsprechend $10 \%$ der vollen Bürette bei kontinuierlich laufendem Motor.

Testansatz

Im $25 \mathrm{~m} l$-Becherglas werden auf $25^{\circ}$ temperiert:

$10 \mathrm{~m} /$ Olivenölemulsion

$3,7 \mathrm{~m} l$ bidest. Wasser $\left(\mathrm{CO}_{2}\right.$-frei)

$0,3 \mathrm{~m} / \mathrm{Na}$-Glykocholatlösung

Start mit $1,0 \mathrm{ml}$ Serum

Der pH-Wert sollte zwischen pH 8,6 und 8,7 liegen, andernfalls wird dieser mit kleinen Volumina $0,1 \mathrm{~N} \mathrm{NaOH}$ oder $0,1 \mathrm{~N} \mathrm{HCl}$ in diesen Bereich gebracht.

Wenn aus der Bürette gleichmäßig Titrationsflüssigkeit in den Ansatz gegeben wird, beginnt man mit der Aufzeichnung des Verbrauchs an $0,01 \mathrm{~N} \mathrm{NaOH}$ auf dem Registrierpapier des Titrigraphen. Bei sehr hohem Enzymgehalt, d. h. oberhalb eines Verbrauchs von $100 \mu l$ Titrationsflüssigkeit pro Minute, wird weniger Serum in den Test eingesetzt und mit bidest. Wasser auf ein Endvolumen von $15 \mathrm{ml}$ aufgefüllt. Im allgemeinen genügt es, den Verbrauch an $0,01 \mathrm{~N} \mathrm{NaOH}$ etwa 5-10 Min. lang aufzuzeichnen.

\section{Ergebnisse}

Dissoziation der Ölsäure

Úber die Dissoziation von in Gummi arabicum-Lösung emulgierter Ölsäure fanden sich keine Angaben (25). Daher wurde die Titrationskurve einer etwa $200 \mathrm{~mm}$ Emulsion von Ölsäure in einer 10 proz. (w/v) Lösung von Gummi arabicum in Wasser aufgenommen (Abb. 1). Die Differenzkurve zwischen der reinen Gummi arabicum-Lösung und der Ölsäureemulsion ergibt einen

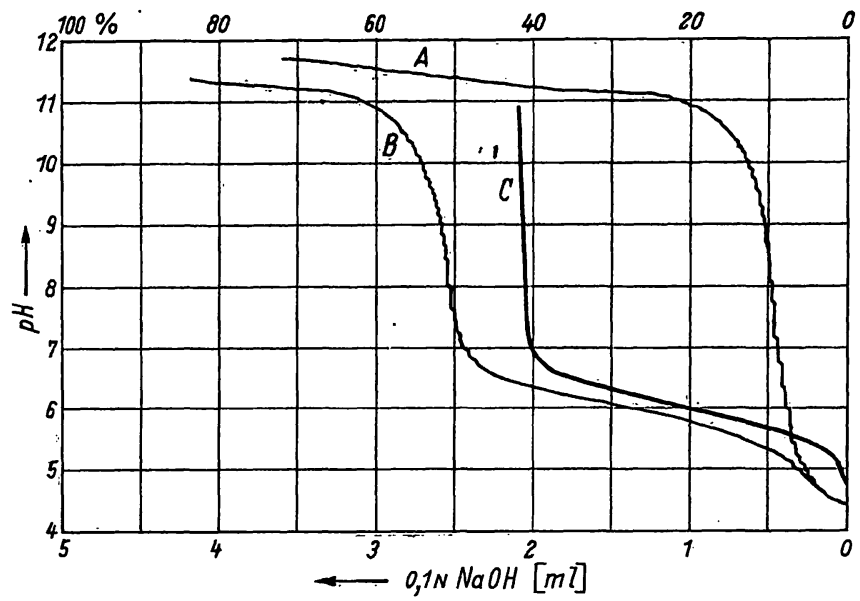

Abb. 1

Titrationskurve von 10proz. Gummi aräbicum-Lösung in Wasser (A) und von Olsäure in 10proz. Gummi arabicum-Lösung homogenisiert (B). Die Differenz stellt die Titrationskurve der ơlsäure dar (C)

$\mathrm{pK}_{\mathrm{a}}^{\prime}$-Wert von 6,0 . Oberhalb von $\mathrm{pH} 8$ sind mithin mehr als $99 \%$ der Ölsäure dissoziiert. Wird Ölsäure aus einer Esterbindung durch enzymatische Hydrolyse freigesetzt, so lassen sich die entstehenden Protonen im $\mathrm{pH}$ Bereich oberhalb von 8 praktisch quantitativ titrieren.

\section{Kinetischer Test}

Den Ablauf des kinetischen Tests zur Bestimmung der Lipaseaktivität des Serums durch kontinuierliche Titration der freigesetzten Fettsäuren zeigen Abbildung 2 (Serum A.R.) und Abbildung 3 (Serum M.H.). Während die Aktivität des Serums A.R. (Registrierung B in Abb. 2) mit $150 \mathrm{mU} / \mathrm{ml}$ entsprechend einem Verbrauch von $15 \mu l 0,01 \mathrm{~N} \mathrm{NaOH}$ pro Minute so gering ist, daß $1,0 \mathrm{~m} l$ Serum in den Test eingesetzt werden kann, kam es bei Verwendung von $1,0 \mathrm{ml}$ Serum M.H. zu einem pH-Abfall im Testansatz, der auch durch Zugabe des größten möglichen Volumens an $0,01 \mathrm{~N}$ Natronlauge pro Zeiteinheit bei der verwendeten Bürette nicht kompen-

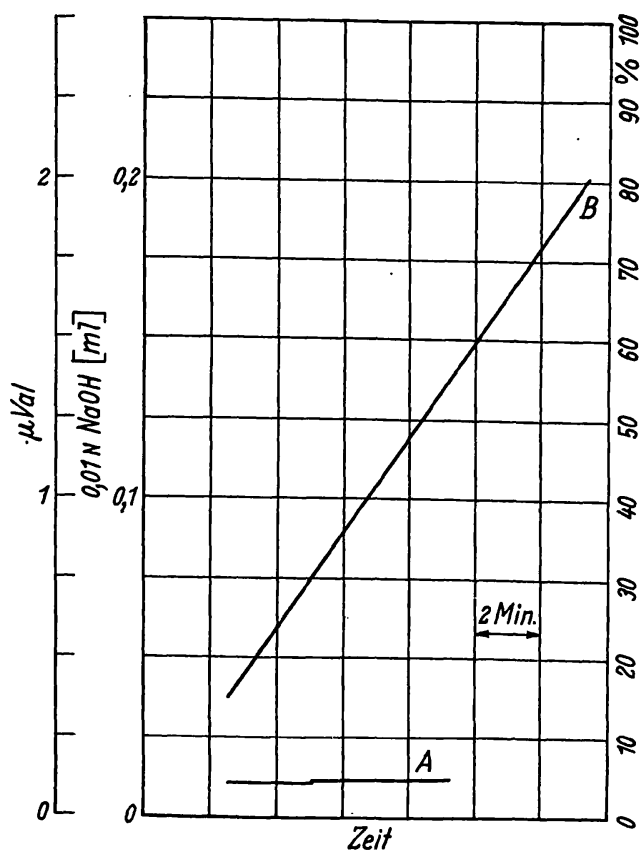

Abb. 2

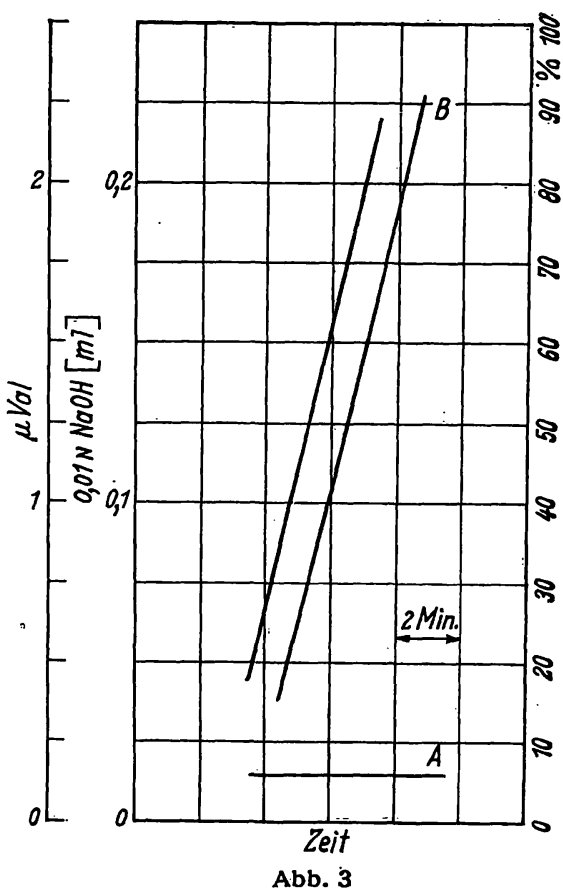

Abb. 2

Kontinuierliche Titration der durch die Wirkung der Serumlipase freigesetzten Fettsäuren

A: Alkaliverbrauch des Substrats ohne Enzym;

B: Aktivität bei Einsatz von $1,0 \mathrm{ml}$ Seruri $(150 \mathrm{mU} / \mathrm{ml})$

Abb. 3

Kontinuierliche Titration der durch Kontinuierliche. Titration der durch gesetzten Fettsäuren

A: Alkaliverbrauch des Substrats ohne Enzym:

B : Aktivität bei Einsatz von $50 \mu l$ Serum $(8800 \mathrm{mU} / \mathrm{ml})$ 
Tab. 1

Aktivitäten von Duodenalsaft, Serum eines Pankreatitispatienten und Leberhomogenat gegenüber verschiedenen Suhstraten. Angabe der Aktivität in $\mathrm{mU} / \mathrm{ml}$

\begin{tabular}{|c|c|c|c|}
\hline & Duodenalsaft & Pankreatitisserum & $\begin{array}{l}\text { Homogenat von menschl. Leber } \\
(20 \text { proz. (wv/v)) }\end{array}$ \\
\hline $\begin{array}{l}\text { Tween } 20 \\
(20 \text { proz. }(v / v) \text { in bidest. Wasser) }\end{array}$ & keine Aktivität & 170 & 21600 \\
\hline $\begin{array}{l}\text { Tween } 80 \\
(20 \text { proz. }(v ! v) \text { in bidest. W'asser })\end{array}$ & keine Aktivität & keine Aktivität & 1970 \\
\hline $\begin{array}{l}\text { Triolein } \\
\qquad(20 \text { proz. }(v / v) \text { in 10proz. wäßr. Gummi arabicum })\end{array}$ & 24000 & 320 & nicht geprüft \\
\hline $\begin{array}{l}\text { Olivenöl } \\
\qquad(20 \text { proz. }(v / v) \text { in 10proz. wäßr. Gummi arabicum) }\end{array}$ & 94000 & 1230 & $\begin{array}{l}40 \\
\text { (fraglich) }\end{array}$ \\
\hline
\end{tabular}

siert werden konnte. Bei der Wiederholung des Tests mit $50 \mu \mathrm{l}$ Serum betrug der Alkaliverbrauch $44 \mu \mathrm{l} / \mathrm{Min}$., so daß sich eine Aktivität von $8800 \mathrm{mU} / \mathrm{ml}$ ergibt (Abb. 3 Registrierung B). Die Zufuhr von Titrationsflüssigkeit erfolgt über mindestens $20 \mathrm{Min}$. geradlinig, aus dem Anstieg der Geraden wird die Anfangsgeschwindigkeit der Reaktion berechnet.

Die hier benutzte Substratlösung ist (siehe unter Methodik) nach dem ersten Mischen nochmals im alkalischen Bereich ( $\mathrm{pH}$ etwa 11) homogenisiert worden. Verwendet man eine ohne diesen zusätzlichen Schritt hergestellte Emulsion und stellt das $\mathrm{pH}$ erst beim fertigen Substrat von etwa $\mathrm{pH} 5$ auf $\mathrm{pH} \mathrm{8,6} \mathrm{ein,} \mathrm{so}$ registriert man in Abwesenheit von Enzym einen Alkaliverbrauch von etwa $0,5-1,0 \mu l$ pro Minute. Dieser Alkaliverbrauch ist durch die im Innern der Olivenöltröpfchen noch vorhandenen freien Fettsäuren bedingt, die offenbar erst beim Homogenisieren im stark alkalischen $\mathrm{pH}$-Bereich neutralisiert werden. Wie die in Abbildung 2 und 3 unter A registrierten Leerwerte mit inaktiviertem Serum (2 Stdn. $56^{\circ}$ ) zeigen, ist eine Spontanhydrolyse unseres Substrats nicht nachzuweisen.

Zur Prüfung der Frage, ob während der Inkubation aus den im Serum enthaltenen Bicarbonationen Hydroxylionen freigesetzt werden, inkubierten wir Serumproben - jeweils $1 \mathrm{ml}$ Serum in Gummi arabicum-Lösung bei $\mathrm{pH} 8,6$; dabei trat kein $\mathrm{pH}$-Anstieg auf und aus der mit $0,01 \mathrm{~N}$ Salzsäure gefüllten Autobürette wurde keine Titrationsflüssigkeit verbraucht. $\mathrm{Zu}$ Ansätzen mit inaktivierten Seren zugefügte Salzsäure konnte zu 95 bis $102 \%$ zurücktitriert werden.

\section{Ausarbeitung optimaler Meßbedingungen Art des Substrats}

Der oben beschriebene kinetische Test ermöglicht die vergleichende Untersuchung verschiedener wasserlöslicher und wasserunlöslicher Substrate unter sehr ähnlichen Bedingungen (Tab. 1). Polyoxyäthylen-SorbitanMonolaurat (Tween 20) wird von Leber- und Serumesterasen, nicht jedoch von der im Duodenalsaft in hoher Aktivität enthaltenen Lipase gespalten. Polyoxyäthylen-Sorbitan-Monooleat (Tween 80) ist als Substrat für Lipase ebenfalls völlig ungeeignet, da Duodenalsaft und Pankreatitisserum gegenüber diesem Ester keine Aktivität zeigen; von Leberesterasen wird Tween 80 noch umgesetzt. Typische und spezifische Substrate
Tab. 2

Vergleich von Olivenöl DAB 6 und Olivenöl „Siegfried“ als Substrat für lipolytische Aktivitäten verschiedener Herkunft Angabe der Aktivität in $\mathrm{mU} / \mathrm{m} l$

\begin{tabular}{lrrrr}
\hline & \multicolumn{4}{c}{ Olivenöl } \\
\hline Normalserum & 80 & 75 & 76 & 72 \\
Pankreatitisserum & 565 & 560 & 540 & 545 \\
Postheparinserum & 198 & 205 & 210 & 205 \\
Pankreashomogenat & 14600 & 14800 & 14200 & 14500 \\
\hline
\end{tabular}

für die Lipase im Duodenalsaft und Pankreatitisserum sind Triolein und Olivenöl in Emulsion (4). Worauf die im Vergleich zu Triolein etwa viermal höhere Aktivität des Enzyms bzw. der Enzyme gegenüber Olivenöl beruht, konnte bisher nicht geklärt werden. Gegenüber dem käuflichen Sigma-Lipase-Substrat zeigte Pankreashomogenat (14500 $\mathrm{mU} / \mathrm{ml}$ mit Olivenöl als Substrat) keine Aktivität.

Auf Grund dieser Ergebnisse wurde für die weiteren Untersuchungen Olivenöl als Substrat benutzt. Da konstante Eigenschaften des Substrats die Voraussetzung für die Reproduzierbarkeit des Tests sind, verglichen wir Olivenöl DAB 6 und Oleum olivae neutralisatum sterilisatum (Siegfried, Zofingen/Schweiz) (19) und fanden keinen Unterschied in der Aktivität verschiedener Enzympräparate (Tab. 2). Auch verschiedene Chargen von Olivenöl - sowohl nach DAB 6 wie nach DAB 7 - führten zu den gleichen Ergebnissen.

\section{Einfluß von Emulgatoren}

Unter den von uns geprüften Substanzen waren lediglich Natrium-Dehydrocholat und Polyäthylenglykol 20000 als Emulgatoren für Olivenöl geeignet (Tab. 3). Die Aktivität von Pankreashomogenat gegenüber einer Emulsion von Olivenöl in Dehydrocholatlösung war jedoch außerordentlich gering. Polyäthylenglykol 20000 ist chemisch wesentlich besser definiert als Gummi arabicum; da jedoch die emulgierende Wirkung der Substanz weit geringer als diejenige von Gummi arabicum ist, zogen wir letzteres als Emulgator vor.

Variiert man die Konzentration von Gummi arabicum in der Substratemulsion, so zeigt sich zwischen 5 und 10\% ein geringer Anstieg der Enzymaktivität (Abb. 4); oberhalb von $10 \%$ bleibt die Hydrolyse des Substrats konstant. Da eine 20proz. Gummi arabicum-Lösung bereits sehr viskös ist, so daß der Ansatz schwerer in 
Tab. 3

Prüfung verschiedener Substanzen als Emulgatoren für Olivenöl

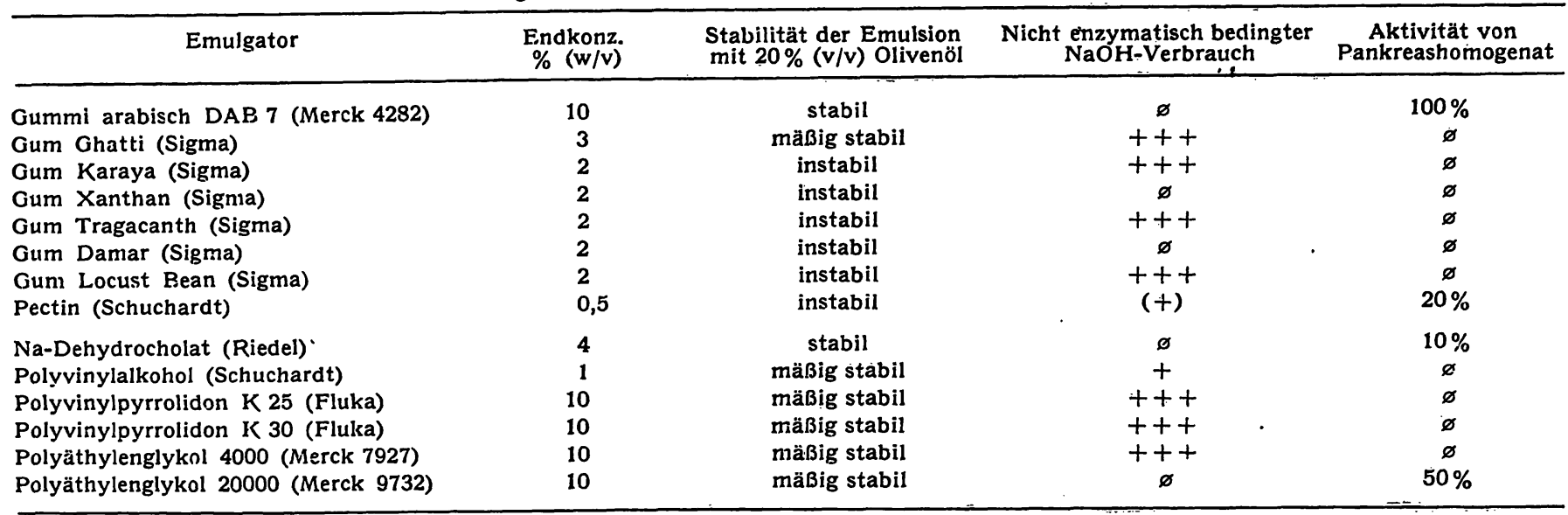

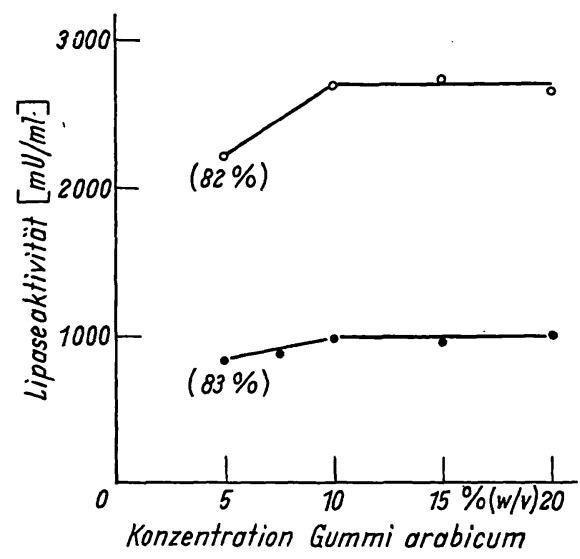

Abb. 4

Abhängigkeit der Lipaseaktivität von der Konzentration des Gummi

arabicum in der Substratemulsion
-. $500 \mu l$ Kontrollserum (Enza-trol) $0100 \mu l$ verd. Pankreashomogenat im Testansatz. Dic Prozentangaben sind auf die maximal meBbare Aktivität bezogen

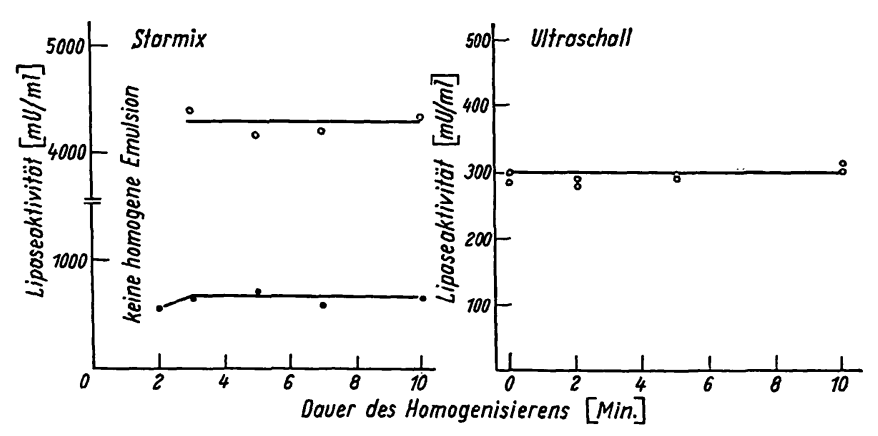

Abb. 5

Abb. 6

Abb. 5

Abhängigkeit der Lipaseaktivität von der Herstellung des Substrats (Dauer des Homogenisierens im Starmix)

-.- $200 \mu l$ Pankreatitis-Serum, $\multimap 100 \mu l$ verd. Pankreashomogenat (10 mg Pankreas/l Normalserum) im Testansatz

Abb. 6

Abhängigkeit der Lipaseaktivität von der Herstellung des Substrats (Zusätzliche Einwirkung von Ultraschall auf 7 Min. lang im Starmix homogenisiertes Substrat); $500 \mu l$ Pankreatitis-Serum im Testansatz

optimaler Weise zu rühren ist, verwendeten wir weiterhin eine 10 proz. (w/v) Lösung von Gummi arabicum zur Herstellung des Substrats.

Homogenisiert man die Mischung von Olivenöl und Gummi arabicum-Lösung verschieden lang, so ergibt sich nach 3 Min. langer Behandlung mit dem Starmix bereits eine optimale Aktivität von Pankreatitisserum bzw. Pankreashomogenat (Abb. 5). Zur Erreichung einer möglichst stabilen Emulsion wurde stets $7 \mathrm{Min}$. lang homogenisiert. Die Aktivität von Pankreatitisserum gegenüber der so nach standardisierter Vorschrift hergestellten Substratemulsion läßt sich auch durch zusätzliche Anwendung von Ultraschall nicht mehr steigern (Abb. 6). Auch durch Homogenisieren mit Gallensäuren und Gummi arabicum-Lösung wird die Geschwindigkeit der Hydrolyse von Olivenöl durch Pankreaslipase nicht erhöht.

\section{Einfluß der Substratkonzentration}

Die bei pH 8,6 und verschiedenen Substratkonzentrationen gemessenen Reaktionsgeschwindigkeiten wurden nach Hofstee (26) gegen den Quotienten aus der Reaktionsgeschwindigkeit und der jeweiligen Substratkonzentration $v / \mathrm{S}$ aufgetragen (Abb. 7), da dies die genaueste Methode für die Ermittlung der Michaeliskonstanten $K_{\mathrm{m}}$ und der maximalen Reaktionsgeschwindigkeit $V$ ist (27).

Da Olivenöl keine einheitliche Substanz darstellt, so daß kein Molekulargewicht berechnet werden kann, ist die Substratkonzentration in Prozent ( $v / v)$ angegeben; die Michaeliskonstante der Lipase im Serum eines wegen akuter Pankreatitis eingewiesenen Patienten ergibt sich zu $K_{\mathrm{m}}=0,34 \%$ Olivenöl. Eine Hemmung durch hohe Substratkonzentrationen ist nicht festzustellen. Die maximale Reaktionsgeschwindigkeit für das verwendete Serum beträgt $V=635 \mathrm{mU} / \mathrm{ml}$; unter unseren Testbedingungen werden $v=620 \mathrm{mU} / \mathrm{m} l$ oder $98 \%$ von $V$ gemessen.

\section{pH-Optimum}

Variiert man am Titrator den Titrationsendpunkt und damit die Wasserstoffionenkonzentration, bei der die enzymatische Reaktion abläuft, so ergibt sich für die Lipase im Serum eines Patienten mit akuter Pankreatitis ein breites $\mathrm{pH}$-Optimum zwischen $\mathrm{pH} 8,6$ und 9,0 (Abb. 8). Für das Standardiv̈erfahren wurde $\mathrm{pH} 8,6$ gewählt, da bei diesem $\mathrm{pH}$ die möglichen Störungen durch Kohlendioxyd der Raumluft am geringsten sind. 


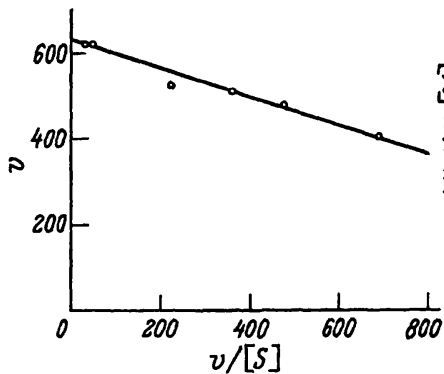

Abb. 7

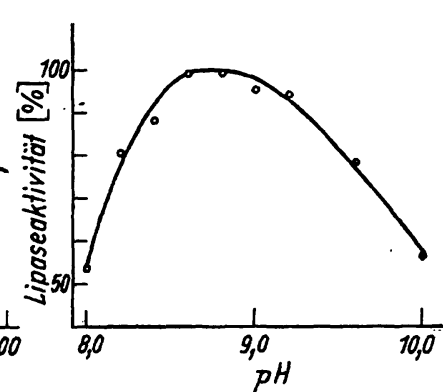

Abb. 8
Abb. 7

Abhängigkeit der Aktivität der Serumlipase von der Olivenölkonzentration $\%(v / v)$. Auftragung nach HOFSTEE; Pankreatitis-Serum $(620 \mathrm{mU} / \mathrm{ml}$ unter Standardbedingungen)

Abb. 8

Abhängigkeit der Aktivität der Serumlipase vom pH

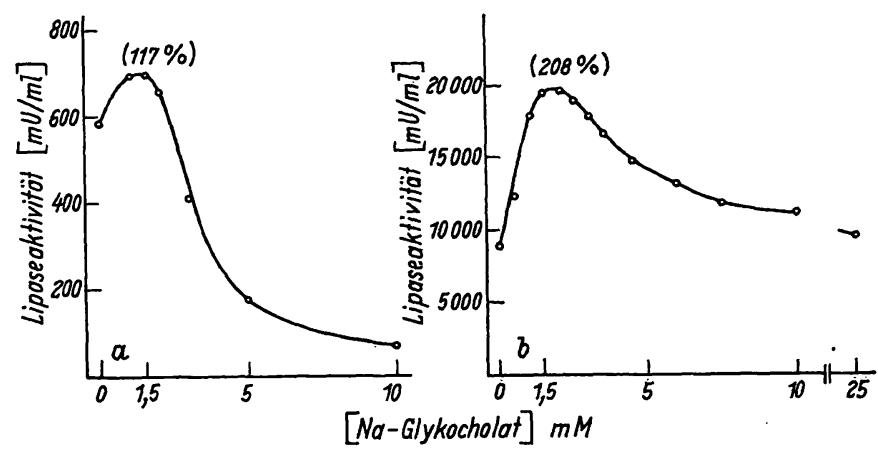

a

Abb. 9

Abhängigkeit der Aktivität der Serumlipase von der Natrium-Glykocholatkonzentration

a) $1,0 \mathrm{ml}$ Pankreatitis-Serum pro Test; b) $20 \mu l$ Pankreatitis-Serum Die Prozentangaben sind auf die Aktivität in Abwesenheit von NaGykocholat bezogen

\section{Einfluß von Gallensäuren}

Da reines ${ }^{1}$ ) Natrium-Taurocholat (Calbiochem 5802 17, dünnschichtchromatographisch einheitlich) die Hydrolyse von Olivenöl durch Pankreatitisserum um etwa $20 \%$ hemmt, Natrium-Glykocholat (Calbiochem 3605 12, dünnschichtchromatographisch einheitlich) dagegen zu einer Erhöhung der Aktivität führt, wurde der Einfluß von Glykocholat eingehend untersucht. Es zeigte sich dabei, daß die aktivierende Wirkung des Glykocholats nicht nur von der Glykocholatkonzentration, sondern auch von dem in den Test eingesetzten Serumvolumen abhängt (Abb. 9). Während es bei einer Serummenge von $1,0 \mathrm{~m} l$ durch Glykocholat nur zu einer Steigerung der Aktivität auf maximal etwa $118 \%$ des Ausgangswertes kommt (Abb.9a), ergibt sich bei Einsatz von nur $20 \mu l$ eines entsprechend lipasereichen Serums (Abb. 9b) eine wesentlich stärkere Aktivierung auf etwa $210 \%$ bei einer optimalen Glykocholat-Endkonzentration von $1,5 \mathrm{~mm}$. In Anwesenheit höherer Glykocholatkonzentrationen wird die Hydrolyse des

1) Reine Taurocholsäure ist farblos (28); die meisten der angebotenen Präparate sind jedoch stark verunreinigt, so daß die mit diesen Substanzen exhaltenen Ergebnisse nicht zu interpretieren sind.
Olivenöls zunehmend gehemmt. Wie aus Abbildung 10 hervorgeht, kann die durch Glykocholat hervorgerufene Aktivierung zum Teil auch durch Zusatz von inaktiviertem Serum oder von Humanalbuminlösung bewirkt werden. In allen Testreihen (Abb. 10), einmal ohne Zusatz enzymatisch inaktiven Proteins, zum anderen mit jeweils $0,5 \mathrm{~m} l$ inaktiviertem Serum, mit $0,5 \mathrm{~m} l$ und mit $1,0 \mathrm{ml}$ einer 4 proz. Humanalbuminlösung, erwies sich eine Glykocholatkonzentration von $1,5 \mathrm{~mm}$ als optimal, so daß diese Konzentration für den Standardtest gewählt wurde. Unter diesen Bedingungen ist der Einfluß der Proteinkonzentration im Test praktisch zu vernachlässigen.

\section{Einfluß von Calciumionen}

$\mathrm{Da}$ in mehreren Vorschriften zur Bestimmung der Lipaseaktivität Calciumionen im Testansatz enthalten sind (Übersicht bei WiLls (1)), prüften wir auch die Abhängigkeit der Enzymaktivität vom Gehalt des Inkubationsansatzes an $\mathrm{Ca}^{++}$(Abb. 11). In Ansätzen ohne Glykocholat żeigen Calciumionen keinen aktivierenden

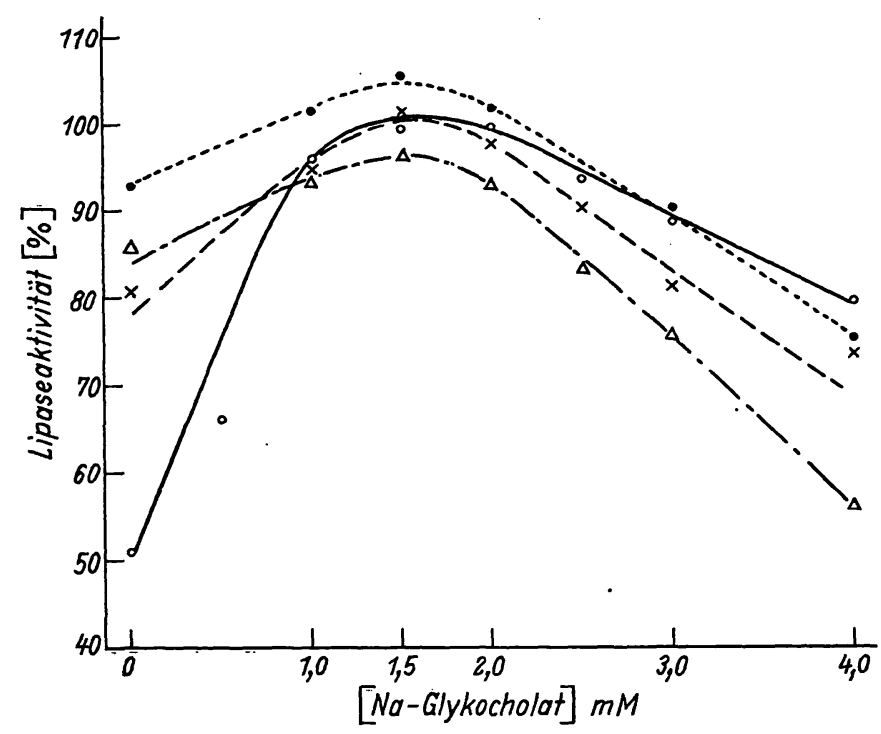

Abb. 10

Abhängigkeit der Aktivität der Serumlipase (20 $\mu l$ PankreatitisSerum $(21000 \mathrm{mU} / \mathrm{ml}$ ) pro Test) von der Natrium-Glykocholat- und der Proteinkonzentration.

$\circ$ ohne Zusatz; 0. Zusatz von $0,5 \mathrm{ml}$ inaktiviertem Serum; $1,0 \mathrm{ml} 4$ proz. Humanalbumin

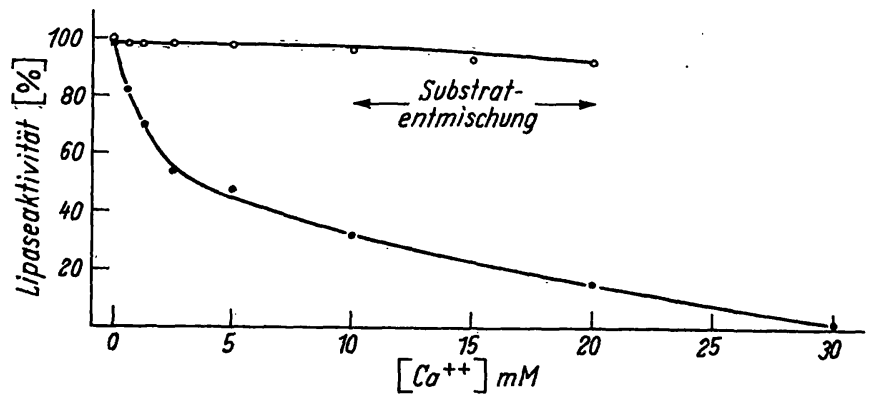

Abb. 11

Abhängigkeit der Aktivität der Serumlipase $(1,0 \mathrm{ml}$ PankreatitisSerum $(620 \mathrm{mU} / \mathrm{ml})$ pro Test) von der Calciumkonzentration $\longrightarrow$ ohne Natrium-Qlykocholat; $\longrightarrow$ mit $1,5 \mathrm{~mm}$ NatriumGlykocholat 
Effekt, oberhalb von $10 \mathrm{mM} \mathrm{CaCl}{ }_{2}$ nimmt die Olivenölspaltung geringfügig ab. Enthält das Testmedium jedoch Glykocholat in der optimalen Konzentration von 1,5 mM, so bewirken Calciumionen eine starke Hemmung der enzymatischen Hydrolyse des Substrats, die exponentiell abfällt und bei $30 \mathrm{~mm} \mathrm{Ca}^{++}$nicht mehr nachweisbar ist. Außerdem zeigt sich bei hohen Calciumchloridkonzentrationen eine Entmischung der Substratemulsion. Es wurden daher keine Calciumsalze in den Test eingesetzt.

\section{Einflüs von Natriumcblorid}

Nach Brown, Boyle und ANFinsen (29) läßt sich die im Postheparinplasma nachweisbare Lipase $^{2}$ ) durch $\mathrm{Na}$ triumchlorid in hohen Konzentrationen hemmen. Zur Charakterisierung der Lipase des Serums von Patienten mit akuter Pankreatitis wurde daher die Aktivität des Enzyms in Gegenwart von $\mathrm{NaCl}$ untersucht (Abb. 12).

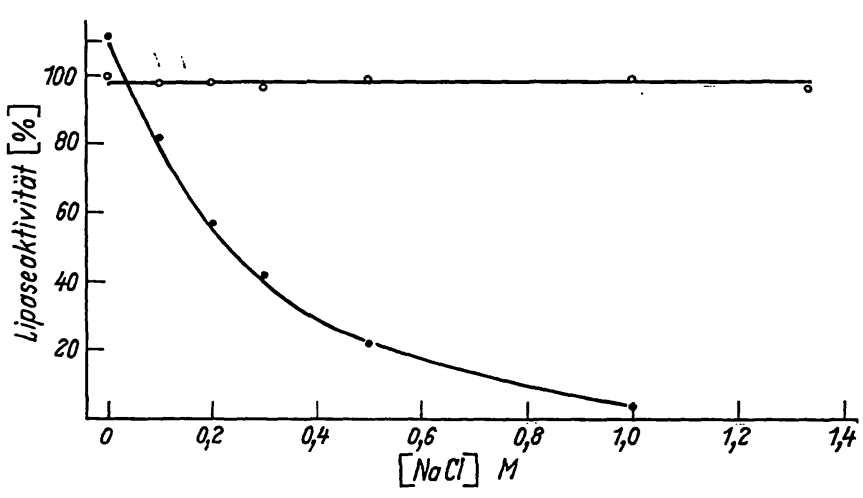

Abb. 12

Abhängigkeit der Aktivität der Serumlipase $(0,5 \mathrm{ml}$ PankreatitisSerum ( $780 \mathrm{mU} / \mathrm{ml})$ pro Test) von der Natriumchloridkonzentration $\multimap$ ohne Natrium-Glykocholat; $\longrightarrow$ mit $1,5 \mathrm{~mm}$ NatriumGlykocholat

Enthält der Testansatz keine Gallensäuren, so hemmt $\mathrm{NaCl}$ bis zu einer Endkonzentration von 1,33 M nicht; in Gegenwart von Glykocholat kommt es - ähnlich wie oben beim Calcium - zu einer ausgeprägten Hemmung, so daß bei einer Konzentration von $1 \mathrm{M} \mathrm{NaCl}$ nur noch $7 \%$ der Ausgangsaktivität gemessen werden. Ebenso wie

2) „Lipoproteidlipase“; da die Spezifität des Enzyms nicht auf Lipoproteine beschränkt ist, sollte anstelle dieses Ausdrucks der Begriff „Postheparinlipase“ benutzt werden (30). bei Calciumchlorid wird eine Substratentmischung beobachtet. In Abwesenheit von Kochsalz liegt die Aktivierung durch Glykocholat im gleichen Bereich wie in Abbildung 9a.

\section{Einfluß der Enzymkonzentration}

Wie Abbildung 13 zeigt, besteht bei Verwendung von verdünntem Pankreashomogenat als Enzymquelle ein linearer Zusammenhang zwischen eingesetzter Enzymmenge und ermittelter Enzymaktivität bis $z u$ etwa $1500 \mathrm{mU}$. Auch mit Enza-trol ${ }^{3}$ ) verläuft diese Beziehung geradlinig (Abb.14). Setzt man jedoch Serum von $\mathrm{Pa}-$ tienten mit akuter Pankreatitis in den Test ein, so ist die Enzymaktivität nur bis zu $1 \mathrm{~m} l$ Serum pro Test der Enzymkonzentration proportional (Abb. 15); oberhalb dieser Serummenge werden geringere Aktivitäten als erwartet gemessen, und bei mehr als $3 \mathrm{ml}$ Serum pro Test nimmt die Aktivität nicht mehr weiter zu. Dialysiert man das Serum $15 \mathrm{Stdn}$. bei $+4^{\circ}$ gegen 0,9proz. (w/v) $\mathrm{NaCl}-L$ ösung, so bleibt die Proportionalität bis zu $3 \mathrm{ml}$ Serum pro Test erhalten, ein Befund, der für das Vorkommen eines dialysierbaren Hemmstoffs im Serum spricht.

In weiteren Versuchen wurden zu jeweils $0,5 \mathrm{~m} /$ gering aktiven Seren im Test 20-50 $\mu \mathrm{l}$ Serum mit hoher Lipaseaktivität zugesetzt; die gemessenen Aktivitäten entsprachen der Summe der Ausgangsaktivitäten.

\section{Haltbarkeit}

Die Stabilität des Enzyms im Serum wurde bei Raumtemperatur und bei $+4^{\circ}$ während 4 Wochen geprüft; es zeigte sich dabei keine verminderte Aktivität gegenüber dem Ausgangswert. In den bei $-20^{\circ}$ eingefrorenen Serumproben fand sich auch nach 3 Jahren noch kein Aktivitätsverlust. Abbildung 16 zeigt die über 4 Wochen kontrollierte Aktivität von eingefrorenem Serum. Durch zweistündige Inkubation bei $+56^{\circ}$ läßt sich das Enzym vollständig inaktivieren.

3) Nach persönlicher Mitteilung von Dade Reagents Inc. über die Herkunft des lipolytischen Enzyms in dem in Abbildung 14 verwendeten Enza-trol handelt es sich um Lipase aus Schweinepankreas. Beginnend mit Charge ET-233 enthält die Zusammenstellung der Aktivitäten jetzt auch Angaben über die Organe, aus denen die betr. Enzympräparate dargestellt wurden.

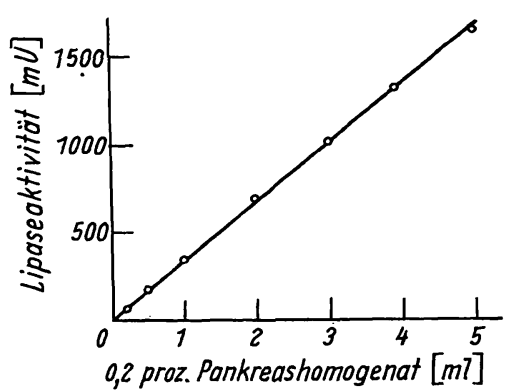

Abb. 13

Abhängigkeit der Lipaseaktivität von der Enzymkonzentration. Pankreashomogenat

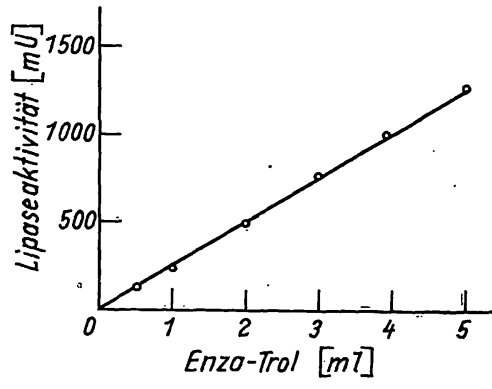

Abb. 14

Abhängigkeit der Lipaseaktivität von der Enzymkonzentration. Kontroll-

Angabe der Aktivität in mU/Ansatz

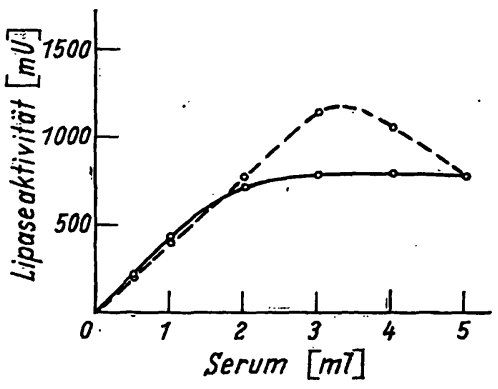

Abb. 15

Abhängigkèit der Lipaseaktivität von der Enżymkonzentration $\circ$ Pankreatitisserum; O-..० Pankre15 Stdn bei $4^{\circ}$ gegen 0,9 . proz. Natriumchloridlösung dialysiert 


\title{
Mikromethoden
}

\section{für das klinisch-chemische und biochemische Laboratorium}

\author{
von Dr. med. Hermann Mattenheimer \\ Associate Professor of Biochemistry, University of Illinois, College of Medicine, \\ Senior Biochemist, Presbyterians-St. Luke's Hospital, Chicago, Ill. USA
}

2., völlig neubearbeitete und erweiterte Auflage

Mit 35 Abbildungen. Oktav. XVI, 223 Seiten. 1966. Plastikeinband DM 30,-

Eine klare, gut durchdachte Darstellung einiger heute in den meisten klinischen Laboratorien üblichen Mikromethoden, nach der ohne weiteres gearbeitet werden kann. Das Büchlein sollte von jedem gelesen werden, ehe er sich ein Labor einrichtet, zumal wegen des ausführlichen Kapitels über verschiedene Mikroliter-Einrichtungen.

Medirinische Monatsschrift, Stuttgart

Die Methoden sind kurz gehalten mit Angaben der einschlägigen Literatur. Sie sind alle vom Autor in langjähriger Erfahrung erprobt und bürgen dafür, daß sie auf Anhieb durchführbar sind. Jemand, der sich ohne eigene persönliche Erfahrung für: mikroanalytische Methoden in der klinischen Chemie und Biochemie interessiert, findet hier eine kurze prägnante Darstellung die sicher ihre guten Dienste leisten wird.

Enzymologia Biologica et Clinica, Basel

\section{Walter de Gruyter \& Co • Berlin 30}

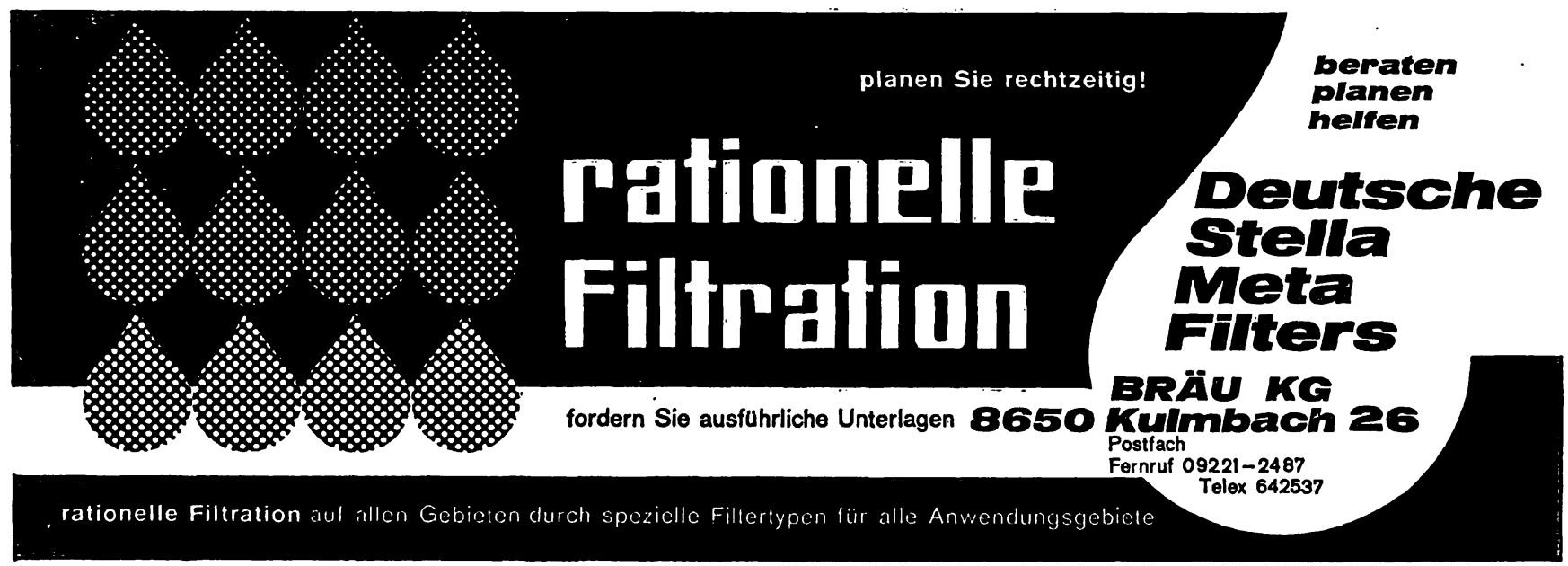




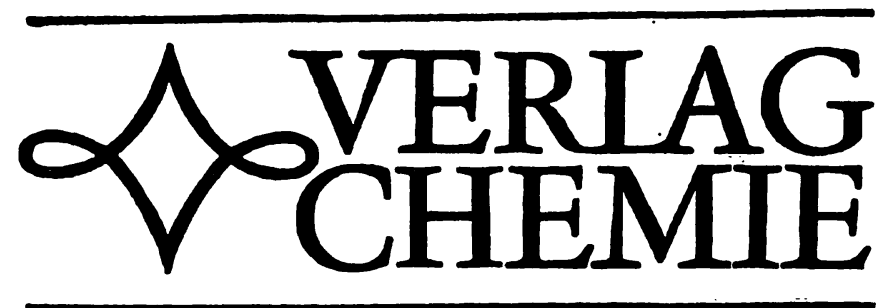

Eine neue, leicht faßliche Darstellung mit praktischen und theoretischen Aufgaben:

Arnim Henglein - Wolfram Schnabel Jürgen Wendenburg

\section{Einführung} in die Strahlenchemie

\section{Mit praktischen Anleitungen}

\section{U'ber dieses Buch:}

Aufgabe des vorliegenden Werkes ist es, dem Chemiker das Verständnis der Strahlenreaktionen zu vermitteln, um ihm ein Hilfsmittel für reaktionskinetische Studien zu geben und ihm die Anwendung von Strahlung zur chemischen Synthese zu ermöglichen. Durch die leicht faßliche Darstellung der verschiedenen Aspekte wird ferner Biologen, Biophysikern und Medizinern, die biologische Strahleneffekte untersuchen, das Erarbeiten der physikalischen und chemischen Grundlagen erleichtert. Eine weitere Aufgabe des Buches besteht darin, den Leser mit den heute als sicher erkannten Ergebnissen der Strahlenchemie vertraut zu machen und ihn auf noch nicht endgültig geklärte Probleme hinzuweisen.

Die am Ende der Kapitel gestellten praktischen und theoretischen Aufgaben und ihre Lösungen im Anhang dienen als Illustration und zur praktischen Einführung in die jeweils behandelten Probleme. Der größte Teil der praktischen Aufgaben ist so abgefaßt, daß sie im physikalisch-chemischen Praktikum eines Universitätsinstituts gestellt werden können. In den exsten sieben Kapiteln sind Strahlenquellen, Strahlenabsorption, Dosimetrie und Ionisationseffekte in Gasen und Flüssigkeiten beschrieben, denn diese Kenntnisse der Strahlenphysik bilden eine unerläßliche Voraussetzung für strahlenchemische Arbeiten. Die Besprechung von Reaktionen angeregter Molekeln und Ionen schließt sich an, wobei auch die grundlegenden Ergebnisse aus der Photochemie und der chemischen Massenspektrometrie behandelt werden. Der Strahlenchemie wäßriger Systeme sind fünf Kapitel gewidmet. Hier findet der Leser eine eingehende Besprechung der Pulsradiolyse und eine Erörterung chemischer Aspekte der Strahlenbiologie. An Hand der Kohlenwasserstoffe wird die Einwirkung energiereicher Strahlung auf organische Stoffe diskutiert. Weitere Beispiele enthält das Kapitel über präparative und technische Strahlenchemie. Auch den Strahlenreaktionen in festen Stoffen, insbesondere in organischen Gläsern bei tiefer Temperatur, wird Raum gegeben. Die drei letzten Kapitel umfassen die Polymerisation und das Verhalten von Kunststoffen unter Strahlung. Die angegebenen Literaturzitate führen den Leser in die Spezialliteratur ein.

1969. X, 400 Seiten mit 124 Abbildungen und 29 Tabellen. Kunststoffeinband DM 45.-

Wir ibersenden Ihnen gern unsiren Sonderprospekt mit Inhaltsverzeichnis.

VERLAG CHEMIE - GMBH WEINHEIM/BERGSTR.
ARBEITSMETHODEN

DER MODERNEN NATURWISSENSCHAFTEN

Herausgegeben von Prof. Dr. KURT Fischbeck

\section{Wenzel-Schulze}

\section{Tritium-Markierung}

Darstellung, Messung und Anwendung nach Wilzbach ${ }^{3} \mathrm{H}$-markierter Verbindungen

Von Martin Wenzel, Physiologisch-Chemisches Institut der Freien Universität Berlin, und P. Eberhard Schulze, Hauptlaboratorium der Schering AG., Isotopenabteilung Berlin

Oktav. Mit 62 Abbildungen und 42 Tabellen. XII, 176 Seiten. 1962. Plastikeinband DM 26,-

Das Buch wird ein wertvoller Berater weiter Fachkreise sein und trägt bedeutend zur vollständigen Ausnützung der günstigen Eigenschaften dieses Isotops bei.

Das Erscheinen dieses Buches ist ein wesentlicher Beitrag zur einstweiligen noch spärlichen deutschen radiochemischen Literatur.

Klinische Wochenschrift

\section{Dorfner}

\section{Ionenaustauscher}

\section{Eigenschaften und Anwendungen}

\section{Von Dr. phil. Konrad Dorfner Diplom-Chemiker}

2., neubearbeitete und erweiterte Auflage

Mit 58 Abbildungen und 27 Tabellen.

Oktav. VIII, 208 Seiten. 1964. Plastikeinband DM 28,-

Die knappe Form der Darstellung wie auch die übersichtliche Gliederung und Beifügung von ausgewählten wesentlichen Tabellen und Abbildungen ermöglicht die rasche Information über Ionenaustauscher und ihre Anwendung. Dabei erweisen sich die als Beispiele für die Anwendung dargestellten Arbeitsvorschriften als wertvolle Ergänzung.

Berichte ï̈ber die gesamte Biologie 


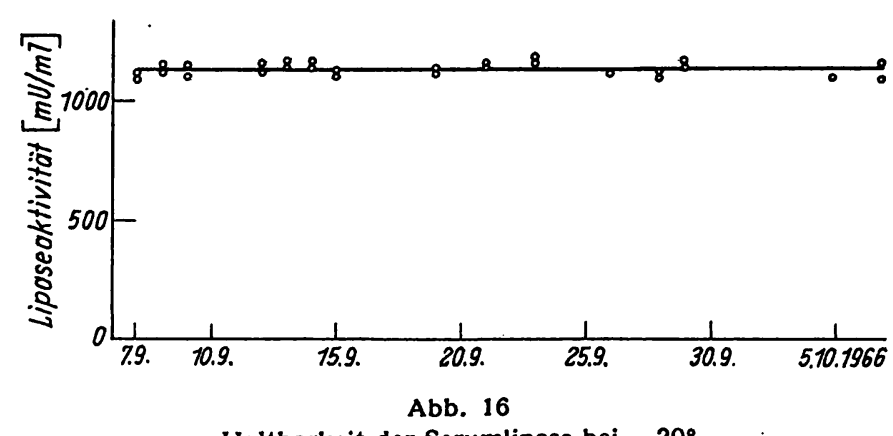

Haltbarkeit der Serumlipase bei $-20^{\circ}$

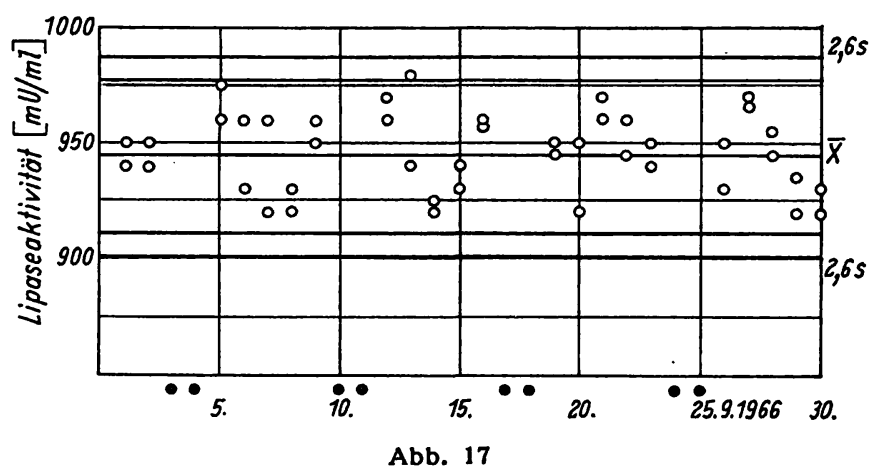

Präzisionskontrolle der Serumlipasebestimmung mit Enza-trol Kontrollkarte

\section{Präzisionskontrolle}

Als Kontrollprobe zur Präzisionskontrolle eignet sich Enza-trol ${ }^{3}$ ) (Abb. 17). Der Variationskoeffizient in dem dargestellten Zeitabschnitt betrug $\mathrm{VK}=3 \%$. Da die Analysendaten der Herstellerfirma über die lipolytische Aktivität dieses Kontrollserums mit anderer Methodik gewonnen wurden, ist eine Richtigkeitskontrolle mit Enza-trol bisher nicht möglich.

\section{Normbereich}

Bei 126 Pankreasgesunden fanden sich Lipaseaktivitäten von $11-138 \mathrm{mU} / \mathrm{ml}$ Serum. $\mathrm{Da}$ die Werte nur bei Eintragung in ein Wahrscheinlichkeitsnetz mit logarithmisch geteilter Abszisse durch eine Gerade dargestellt werden konnten, liegt eine logarithmisch-normale Verteilung wie bei zahlreichen anderen Serumbestandteilen vor (31). Der Mittelwert der lipolytischen Aktivität ergibt sich zu $\overline{\mathbf{x}}=51 \mathrm{~m} \mathrm{U} / \mathrm{m} l$, die untere Grenze des Normbereichs $z u \quad \bar{x}-2 s=18 \mathrm{mU} / \mathrm{m} l$ und die obere Grenze $z u \bar{x}+2 s=141 \mathrm{mU} / \mathrm{ml}$. Auch die an 381 stationären Patienten ohne Anhalt für eine Pankreaserkrankung ermittelten Aktivitäten zeigten eine logarithmisch-normale Verteilung; dieser Bereich ist durch folgende Zahlen charakterisiert: $\overline{\mathbf{x}}=60 \mathrm{mU} / \mathrm{ml}, \overline{\mathrm{x}}-2 \mathrm{~s}$ $=23 \mathrm{mU} / \mathrm{m} l$ und $\overline{\mathrm{x}}+2 \mathrm{~s}=162 \mathrm{mU} / \mathrm{m} l$.

\section{Diagnostische Bedeutung der Serumlipase}

Auf die diagnostische Wertigkeit der hier beschriebenen Methode kann nur kurz eingegangen werden. Im Serum von 18 Patienten, die wegen akuter Pankreatitis stationär behandelt wurden, fanden sich als jeweils höchste Aktivitäten Werte zwischen 1050 und $20600 \mathrm{mU} / \mathrm{ml}$; der Mittelwert von $4920 \mathrm{mU} / \mathrm{m} /$ liegt beim 35 fachen der oberen Grenze des Normbereichs (32). Auf Grund der
Elimination des Enzyms aus dem Serum bei einer Patientin mit akuter Pankreatitis bei passagerem Verschlußikterus konnte die Halbwertszeit der Pankreaslipase zu 16 Stdn. berechnet werden (23); diese Zeit entspricht etwa der aus klinischen Verlaufsbeobachtungen ermittelten Halbwertszeit der Aspartattransaminase (33).

Zur Frage des Vorkommens lipolytischer Enzyme im Harn

Untersucht man Harn von Gesunden und von Pankreatitispatienten in dem hier beschriebenen Test auf lipolytische Aktivität, so wird - wie bei der Lipasebestimmung - geradlinig mit der Zeit Alkali durch die Autobürette zugegeben, d. h. es entstehen Wasserstoffionen, die titriert werden. Der gleiche Alkaliverbrauch findet sich jedoch auch in Ansätzen ohne Olivenöl; durch 10 Min. langes Kochen des Harns nimmt die Zugabe von Titrationsflüssigkeit nicht ab. Dialysiert man den Harn 16 Stdn. bei $+4^{\circ}$ gegen mehrfach gewechseltes bidest. Wasser, so ist in Testansätzen mit und ohne Olivenöl gleichermaßen kein Alkaliverbrauch mehr nachweisbar. Auf Grund dieser Befunde kann das Vorkommen von Lipaseaktivitäten im Harn ausgeschlossen werden.

\section{Diskussion}

Mit angereicherten Präparationen von Lipase aus Schweinepankreas konnte gezeigt werden, daß das Enzym nur auf Substrate in Emulsion wirkt (4). Wasserlösliche Fettsäureester sind als Substrate nicht geeignet; Versuche, die Aktivitätsbestimmung mit $\beta$-Naphthylestern von Fettsäuren verschiedener Kettenlänge $\left(C_{12}\right.$ (6); $C_{9}(7) ; C_{14}(9)$ ) dadurch spezifisch für Lipase $z u$ machen, daß man die Enzymreaktion einmal ohne Gallensäuren, einmal in Anwesenheit von Gallensäuren ablaufen läßt, haben nicht zu einem anerkannten Verfahren geführt. Auf Grund der großen Empfindlichkeit fluorometrischer Methoden wären die Hydrolyse von Fluoresceindiestern $(8,10)$ und von 4 -Methylumbelliferonestern (34) geeignete und leicht $\mathrm{zu}$ messende Reaktionen; Fluoresceindiacetat wird jedoch ebenso wie Fluoresceindicapronat nur von einer gereinigten Esterase aus Rattenpankreassekret gespalten, Fluoresceindioleat dagegen weder von dieser Esterase noch von gereinigter Lipase gleicher Herkunft (35). Nach BarrowmaN und BORGSTRÖM (35) sind auch 4-Methylumbelliferonester keine für Lipase spezifischen Substrate. $p$-Nitrophenylester kommen ebenfalls nicht in Frage, da sie von Lipase und von Esterase umgesetzt werden (35).

Unter den wenig wasserlöslichen Substraten ist Tributyrin nach klinischen Untersuchungen nicht brauchbar, da Patienten mit akuter Pankreatitis keine erhöhten Enzymaktivitäten im Serum aufweisen $(36,37)$. Wird Olivenöl als Substrat benutzt, so liegt es meist in Form einer Emulsion in Gummi arabicum-Lösung o. ä. vor. Mit Verfahren, in denen das Substrat nicht - oder zumindest nicht während der gesamten Testdauer - 
emulgiert ist (BoRgströsı $(12,38)$ ), können keine maximalen Reaktionsgeschwindigkeiten gemessen werden, da die Enzymaktivitāt bis zur Substratsāttigung stark von der Größe der Grenzfläche Öl/Wasser abbängt (39) und eine solche Sättigung nicht - oder zumindest zu Beginn des Tests nicht - vorliegt. Ergebnisse mit diesen Meßverfahren sind daher mit den hier dargestellten Befunden nicht vergleichbar. In neuerer Zeit wird jedoch auch von BORGSTRÖM und Mitarbeitern mit emulgierten Substraten wie Triolein gearbeitet (40).

Triolein hat gegenüber Olivenöl den Vorteil, eine chemisch einheitliche Substanz darzustellen. Die Spaltung von Triolein durch Lipase ist jedoch - unabhāngig von der Herkunft des Enzyms (Duodenalsaft oder Pankreatitisserum) - so niedrig, daß eine ausreichend genaue Bestimmung der Hydrolysegeschwindigkeit durch Seren mit normaler oder gering erhöhter Aktiritāt nicht möglich ist. Worauf der Unterschied zwischen Olivenöl und Triolein beruht, ist noch ungeklärt. Auch aus den Untersuchungen von CLEMIENT, Clement und Bezard (41) ergibt sich kein Hinweis auf ein optimales Substrat. Wir schlagen vor, bis zur Ermittlung einer chemisch einheitlichen Substanz, die mit ausreichender Geschwindigkeit und mit gleicher Spezifitāt wie Olivenöl gespalten wird, letzteres als Substrat für Lipase zu benutzen.

Die Dissoziation der schwer wasserlöslichen langkettigen Fettsāuren hängt von den Lösungsbedingungen ab. Berücksichtigt man diese Bedingungen nicht, so sollte der $\mathrm{pK}_{\mathrm{a}}^{\prime}$-Wert unsubstituierter langkettiger Fettsāuren bei 4,8 liegen (42). In Untersuchungen zur Hydrolyse ron Monoglyceriden bestimmten HofManN und BORGSTRöM den $\mathrm{pK}_{\mathrm{a}}^{\prime}$-WWert der Ölsāure in micellarer Lösung, die gleichzeitig Monoolein und Natrium-Taurodesoxycholat enthielt, zu 6,9 (43). Auch aus Befunden, die an durch Ultrafiltration dargestellten micellaren Ölsãuredispersionen in Gallensãurelösungen gewonnen wurden, ließ sich ein $\mathrm{pK}_{\mathrm{a}}^{\prime}$-Wert von etwa 7,0 berechnen (44). Der Unterschied zu dem hier gefundenen Wert von 6,0 kann durch die unterschiedliche Emulgierung bedingt sein.

$\mathrm{Da}$ nach den Empfehlungen der Enzymkommission der Internationalen Union für Biochemie (22) gearbeitet werden sollte, können nephelometrische Verfahren (17) nicht angewandt werden, bei denen ein definierter Substratumsatz nicht zu messen ist.

Eine Spontanhydrolyse des Olivenöls war während der Meßdauer nicht nachzuweisen. Ob eine solche Spontanhydrolyse bei den diskontinuierlichen Testen mit langen Inkubationszeiten eine Rolle spielt, oder ob der Alkaliverbrauch bei der Titration des in diesen Verfahren erforderlichen Leerwerts nur auf den im Ansatz enthaltenen Puffersubstanzen und dem während der Inkubationszeit eingeströmten Kohlendioxyd beruht, kann nicht entschieden werden.

Nach TIETZ, Borden und Stepleton (15) sowie Voged und ZIEve (17) unterscheiden sich die pH-Optima der lipolytischen Enzyme des Normalserums und der Serumlipase bei Pankreaserkrankungen. Dabei ist jedoch zu berücksichtigen, daß die Messung der Reaktionsgeschwindigkeit bei Normalseren wegen der geringen Aktivitāten - insbesondere außerhalb des pH-Optimums - mit großen Fehlern behaftet ist. RoE und BrLer (18) stellen die Abhängigkeit der Reaktion vom Anfangs-pH des Testansatzes dar; zur Konstanthaltung des $\mathrm{pH}$ während der ganzen Testdauer reicht der von ihnen verwendete $0,02 \mathrm{M}$ Trispuffer - vor allem bei hohen Aktivitāten - nicht aus. In der hier beschriebenen Vorschrift wird das als optimal ermittelte $\mathrm{pH}$ wāhrend der gesamten Reaktionszeit konstant gehalten.

Der entscheidende Vorteil des kontinuierlichen Tests liegt darin, daB die Anfangsgeschwindigkeit der enzymatischen Reaktion gemessen wird. Die bisher veröffentlichten Zeit-Umsatz-Kurven verlaufen stets vom ersten Meßpunkt ab gekrümmt, gleichgültig, ob die Reaktion bis zu diesem Zeitpunkt 60 Min. (20), 30 Min. (18) oder 5 Min. (21) gelaufen ist. Daraus ergibt sich, da $B$ mit diesen Verfahren die Anfangsgeschwindigkeit der Hydrolyse des Substrats nicht bestimmt wird. Auf Grund der neuen Methode wurden Fragen zur Aktivierung durch Gallensāuren und Calciumionen sowie zur Hemmung durch Natriumchlorid so geklärt, daB optimale Bedingungen zur Aktivitātsbestimmung der Lipase im Serum von Patienten mit akuter Pankreatitis ausgearbeitet werden konnten. Auf den Zusatz von Gallensāuren kann nicht verzichtet werden, auch wenn deren Einfluß bei Normalserum gering ist. Die Messung von Seren mit hoher Lipaseaktivitāt, bei denen nur ein geringes Probevolumen in den Test eingesetzt werden kann, liefert in Abwesenheit von Gallensāuren nur etwa die Hālfte der bei optimaler Glykocholatkonzentration gemessenen Aktivitāt (Abb. 10). Auf die Einheitlichkeit der verwendeten Gallensãuren ist besonders hinzuweisen; verunreinigte Chargen von Natrium-Taurocholat ergeben oft Effekte, die nicht interpretiert werden können (z. B. bei Matrson und Volpentrein (45)).

Obwohl die Aktivität des Enzyms in Anwesenheit von Calciumionen nicht höher als ohne Calciumzusatz ist, kann Calcium am Reaktionsablauf beteiligt sein; so enthālt die $\alpha$-Amylase aus Schweinepankreas pro Molekül 1 Atom Calcium so fest gebunden, $\mathrm{da} B$ es nur durch Elektrodialyse oder durch Dialyse gegen EDTA-Lösung entfernt werden kann (46). Parallel zum Calciumgehalt kristallisierter $\alpha$-Amylase nimmt dann deren enzymatische Aktivitāt ab. Bei der Bestimmung der Aktivitāt des Enzyms in Körperflüssigkeiten führt Zusatz von Calciumionen zum Testansatz jedoch nicht zu einer Aktivitātssteigerung (47).

$\mathrm{Da}$ nähere Kenntnisse über die Vorgānge an der Grenzflāche Öl - Wasser nicht vorliegen, sollen keine Hypothesen über die gegenseitige Beeinflussung von Substrat, Gallensäuren und Protein sowie über die hemmende Wirkung von Calciumionen und von Natriumchlorid in Gegenwart von Gallensāuren aufgestellt werden.

Soweit in den bisher angegebeinen Methoden der $\mathrm{Zu}-$ sammenhang $z w i s c h e n$ Serummenge und enzymatischer Aktivität geprüft werden konnte, fand sich in den meisten Fällen keine lineare Proportionalität (z. B. bei 
(17); Abb. 2 in (21)). Mischt man Serum eines Gesunden mit Serum eines an akuter Pankreatitis erkrankten $\mathrm{Pa}$ tienten in verschiedenen Verhältnissen und läßt sich die Abhängigkeit der gemessenen Aktivitäten von der Menge Pankreatitisserum im Gemisch durch eine Gerade beschreiben, die durch den Nullpunkt des Koordinatensystems geht (19), so ist daraus zu schließen, daß die Aktivität des Normalserums mit der verwendeten Methode nicht gemessen werden kann, da eine Verdünnung des Pankreatitisserums mit einer enzymatisch nicht aktiven Lösung (z. B. inaktiviertem Serum) das gleiche Ergebnis haben würde.

Mit dem hier ausgearbeiteten Verfahren verläuft der Zusammenhang zwischen Enzymmenge und Aktivität bei Pankreashomogenat und bei einem Kontrollserum
(Enza-trol, 5,1 g Protcin $/ 100 \mathrm{ml}$, elcktrophoretisch nur Albumin nachweisbar) bis zu hohen Aktivitäten linear. Setzt man dagegen Serum in den Test ein, so ist die Olivenölhydrolyse der Serummenge nur bis zu $1 \mathrm{~m} l$ Serum pro Test proportional; da die Bestimmung für die Messung der Aktivität von $1 \mathrm{~m} /$ Serum austeichend empfindlich ist, genügt dieser Bereich für diagnostische Zwecke.

Im Harn konnte eine Lipaseaktivität nicht nachgewiesen werden. Es ist $z u$ diskutieren, ob dic Spaltung von $\beta$-Napthylestern durch Harn (48) möglicherweise von Esterasen bewirkt wird.

Fxl. M. HockeborN danke ich für umsichtige und gewissenhafte Mitarbeit.

\section{Literatur}

1. Wills, E. D., Adv. Lipid Res. 3, 197 (1965). - 2. MArChisMouren, G., L. Sarda und P. Desnuelle, Arch. Biochem. Biophysics 83, 309 (1959). - 3. KRISCH, K., Biochem. Z. 337, 546 (1963). - 4. Desnuelle, P. und P. Savary, J. Lipid Res. 4, 369 (1963). - 5. Bier, M., in Colowick, S. P. und N. O. Kaplan, (Hrsg.), Methods in Enzymology, vol. 1, S. 630, Academic Press New York (1955). - 6. Seligxan, A. M. und M. M. NAcrilas, in: H.-U. Bergmeyer (Hrsg.), Methoden der enzymatischen Analyse, S. 776-778, Verlag Chemie, Weinheim (1962). - 7. KRAser, S. P., L. D. Aronson, M. G. Rosenfeld, M. D. Sulkin, A. Chang und A. M. Selrgman, Arch. Biochem. Biophysies 102, 1 (1963). - 8. Gurlbault, G. G. und D. N. Kramer, Analytic. Chem. 36, 409 (1964). - 9. Kramer, S. P., M. Bartaros, J. N. Karpa, J. S. Mindel, A. Chang und A. M. Seligman, J. Surg. Res. 4, 23 (1964). - 10. Meyer-Bertenrath, J. G. und H. Kafparnik, Hoppe-Scyler's Z. physiol. Chem. 349, 1071 (1968). 11. Cherre, I. S. und L. A. Crandall, Amer. J. Physiol. 100, 266 (1932). - 12. Borgströs, B., Biochim. biophysica Acta (Amsterdam) 13, 149 (1954). - 13. BIeR, M. in: Colowick, S. P. und N. O. Kaplan (Hrsg.), Methods in Enzymology, Vol. 1, S. 628, Academic Press, New York (1955). - 14. HeNRY, R. J.,. in: D. Seligson (Hrsg.), in: Stand. Meth. Clin. Chem. 2, 86 (1958). 15. Tretz, N. W., T. Borden und J. D. Stepleton, Amer. J. Clin. Pathol., 31, 148 (1959). - 16. MucDonald, R. P. und R. O, LePAve, Clin. Chem. (New York), 8, 509 (1962). - 17. Vogez W. C. und L. Zreve, Clin. Chem. (New York) 9, 168 (1963). 18. Roz, J. H. und R. E. Byler, Analytic. Biochem. 6, 451 (1963). 19. Weber, H., Dtsch. med. Wschr. 90, 1170 (1965). - 20. TreT\%, N. W. und E. A. Fiereck, Clin. chim. Acta (Amsterdam) 13, 352 (1966). - 21. Massion, CH. G. und D. Seligson, Amer. J. Clin. Path. 48, 307 (1967). - 22. Report of the Commission on Enzymes of the International Union of Biochemistry, S. 8, Pergamon Press, London (1961). - 23. RICK, . W., in F. W. Schmidt (Hrsg.), Praktische Enzymologic. 2. Konferenz der Gesellschaft für Biologische Chemic, Heidelberg 1967, S. 159-162, Hans Huber,
Bern (1968). - 24. Jacobsen, C. F., J. LeONis, K. LinderstrøaLang und M. Otresen, Mcth. biochem. Analysis 4, 171 (1957). 25. Beilsterns Handbuch der organischen Chemie, 4. Auf., 1. Erg.Werk 2, 189 (1929); 2. Erg.-Werk 2, 429 (1942); 3. Erg.-Wcrk 2, 1387 (1961), Springer-Vcrlag, Berlin. - 26. Hopster, B. H. J., Science 116, 329 (1952). - 27. Dowd, J. E. und D. S. RicGs, J. biol. Chemistry 240, 863 (1965). - 28. Index Merck, 9. Auf., S. 712, E. Merck, Darmstadt 1961. - 29. Brows, R. K., E. Boyle und C. B. Anpinsen, J. biol. Chemistry 204, 423 (1953). 30. Fredrickson, D. S., K. Oso und L. L. Davis, J. Lipid Res. 4, 24 (1963). - 31. Wootron, I. D. P., und E. J. Kinc, Lancet 1953/I, 470. - 32. Rick, W., Verh. Dtsch. Ges. Inn. Med. 74, 230 (1968). - 33. Amelung, D., in F. W. Schmidt (Hrsg.), Praktische Enzymologie. 2. Konferenz der Gesellschaft für biologische Chemie, Heidelberg 1967, S. 149-155, Hans Huber, Bern (1968). 34. Jacks, T. J. und H. W. Kircher, Analytic. Biochem. 21, 279 (1967). - 35. Barrowman, J. A. und B. Borgström, Gastroenterology 55, 601 (1968). - 36. BunCH, L. D. und R. L. EMrRsos, Clin. Chem. (New York) 2, 75 (1956). - 37. Henry, R. J., C. Sobez und S. Berkman, Clin. Chem. (New York) 3, 77 (1957). 38. Borgströs, B., J. Lipid Res. 5, 522 (1964). - 39. Desnuelle, P., Adv. Enzymol. 23, 129 (1961). - 40. Morgav, R. G. H., J. Barrowman, H. Filipek-Wender und B. Borgström, Biochim. biophysica Acta (Amsterdam) 146, 314 (1967). - 41. CLEMent, G., J. Cllement und J. Bezard, Biochem. Biophys. Res. Commun. 8, 238 (1962). - 42. Schisidt-Nielsen, K., Acta Physiol. Scand. 12, Suppl. 37 (1946). - 43. Hopmanv, A. F. und B. Borgström, Biochim. biophysica Acta (Amsterdam) 70, 317 (1963). - 44. BorgströM, B., J. Lipid Res. 8, 598 (1967). 45. Mutrson, F. H. und R. A. Volpenhein, J. Lipid Res. 7, 536 (1966). - 46. SteIN, E. A., J. Hsiv und E. H. FisCher, Biochemistry USA 3, 56 (1964). - 47. Rrck, W. und H.-P. StraBAUER, in: Bergmeyer, H.-U., Methoden der en\%ymatischen Analyse, 2. Auf., im Druck. - 48. Gülzow, M., W. Leithüuser und H.-J. Tretrin, Dtsch. Z. Verd. Stoffw. Krankh. 27, 109 (1967).

Prof. Dr. W. Rick 4 Düsscldorf Moorenstr. 5 